\title{
Public Participation in Environmental Assessment of Development Projects - The Sri Lankan Situation
}

\author{
N.T.S. Wijesekera and N.C. Weerakkody
}

\begin{abstract}
Environmental Impact Assessments (EIA) are meant to identify and evaluate the impacts of projects on the environment and interventions in it. The Environmental Assessment Process is to ensure that environmental concerns are incorporated in development projects for the well being of the environment and this requires public participation throughout the project development process. In literature there are many efforts that had been exerted to identify the rights and necessities with respect to public participation. Also comments have been made by many indicating poor public participation in the EIA process and stating the need to improve the same. Presently there is a need to quantify the present level of public participation in projects in order to enable the understanding of the realities of public participation and to ensure that the best development option is implemented at the earliest possible time.
\end{abstract}

This study was done to look at a significant number of EIA and IEE projects of various Sri Lankan Authorities that underwent the approval procedures. Twenty eight EIA and IEE project reports were studied along with the administrative correspondence files maintained at the environmental authorities. The participation in terms of the sectors, stages, issues, and comments made by the public were looked at and quantifications were done. From the numbers participated it was revealed that the overall public involvement in development projects is very low and the maximum overall participation in these projects is around $42 \%$. The public involvement in scoping was found to be Zero in the studied projects. In EIA projects the public were more concerned about the social impacts.

There is a need to increase public participation irrespective of the nature of it's participation. Then the quality of participation in national projects should be emphasized to ensure the sustainability concerns of all development projects.

\section{Introduction}

The Environmental Impact Assessment of Development Projects is central to the concept of sustainable development where the activities of the present are executed in a manner that would look after the environment in the interests of future generations. In this respect, a tool identified as Environmental Impact Assessment (EIA) has been accepted and incorporated into the project planning and implementation process by many nations throughout the world. In Sri Lanka, EIA was first enacted in 1981 for coast conservation. The National Environment Act (NEA) of Sri Lanka was in place by the year 1980, and EIA was mandated island wide by the amendments made to the Act in 1988 (NEA 1988). The Central Environmental Authority (CEA) is the agency responsible for implementing the provisions under the NEA. The CEA in its efforts to strengthen the EIA process and foster sustainable development has also developed many guidelines (CEA 1993, Wijesekera 1999) which are widely in use. The CEA (1993) includes a flowchart of the EIA process with a clear presentation of all the stages where it could be noted that a significant component of public participation is a necessary component for rational decision making to fulfill the needs of sustainable development. Though Sri Lanka permits greater public access to decision making in environmental issues than most other Asian countries, there are shortcomings that exist in the Sri Lankan system (Withanage 1997). According to NEA, public participation during an EIA is in five stages of which two are optional (CEA 1988). Most of the available literature on public participation highlights the rights and necessities of public participation, comment on the poor 
status of public participation and discuss the ways to increase public participation. There are also points of view that the important opportunity provided for public participation has been used inappropriately by certain NGOs thus leading to delays in project implementation (Jayawickrama 1997). In an environment where there are growing concerns regarding appropriate public participation, it is of great importance to identify the level of participation in EIAs as at present; so that the adequacies and inadequacies could be assessed and future directions could be decided. The present study is an attempt to quantify the level of public participation in Environmental Assessment (EA) so that a clear understanding of the situation could be obtained to identify better solutions for the future. The identification of the concepts, identification of the practice and the level of participation are of utmost importance especially to the engineers because it will lead to successful planning, design and implementation of development projects. At present probably due to inadequate understanding of public participation, most development projects have failed to takeoff. In this backdrop it is prudent to study the numbers, the composition of the public response, and the issues that concern most of the public etc., for the planning and designing of projects for the nation.

\section{Methodology}

In legislation, EA in Sri Lanka applies to prescribed projects that are published by government gazette under the NEA. The prescribed projects are identified in two levels namely Initial Environmental Examination (IEE) and EIA. The decision to carryout an IEE or EIA depends on the significance of environmental impacts. An IEE must identify the possible impacts and assess their intensity whereas an EIA has to assess alternatives to identify the option with the least impact on the environment and indicate measures in Mitigation.

Twenty eight EIA and IEE projects that had undergone formal environmental clearance were identified for the study. The project reports and individual files maintained by environmental authorities were perused to identify the types of data available. Key personnel such as EIA consultants who were involved in the preparation of documents, personnel from Non Governmental Organizations (NGO), were interviewed to obtain data and identify issues. Data obtained from these sources were verified by directly and indirectly contacting the concerned parties (Weerakkody 2000).

Compiled data were subdivided to project type, environment assessment category, stages of environment assessment and groups of the public. Issues raised by the public were classified and their magnitudes were computed using different statistics and quantifiable indicators.

\section{Data and Analysis}

EIA report contents shed some light on public participation prior to the submission of the document. Details pertaining to events such as comments on events after the document was open to the public and information from public hearings were taken from the administration files of different agencies and were listed.

\subsection{Categories of Public}

The number of personnel that had participated in the EA for each project was listed (Table 1). Comments received for projects were classified into groups of public affiliated with the EA process NGO, Youth Organizations (YO), Residents of the Locality (RL), Non Residents $(\mathrm{NR})$, village awakening organizations called Gramodaya Mandala (GM) and Religious Organizations (RO). In case of organizations, the comments by all individuals from each organization were listed as a single representation of that organization. Comments from Non residents and residents were treated as individual entities and were divided on the basis of connected details including addresses etc. In the EIA reports some indicated a number as attendance at meetings with the public. This was taken into the total of "persons participated" in the process (Table 1). Results indicated that in 9 out of 13 projects there had been zero public participation in the case of IEE. In the case of the 15 EIA projects, there had been a public response ranging from 2 to 2973 except in three projects that had zero participation. An observation made during data extraction was that when there is a direct negative impact on the public they have tended to comment but they have not taken an interest to send comments on positive aspects. Only in two of the IEE projects were there significant public responses when compared to 
Table 1: Public Responses and the Persons Participated in the Studied IEE \& EIA Projects

\begin{tabular}{|c|c|c|c|c|c|c|c|c|}
\hline \multirow{2}{*}{ Name of the project } & \multirow{2}{*}{$\begin{array}{c}\text { Persons } \\
\text { Participated }\end{array}$} & \multicolumn{7}{|c|}{ Number of Public Group Responses } \\
\hline & & NGO & YO & $\mathrm{RL}$ & NR & GM & Ro & Total \\
\hline 1. Seethawaka Industrial Estate & 0 & 0 & 0 & 0 & 0 & 0 & 0 & 0 \\
\hline 2. Prawn Culture Project, Madilla & 30 & 2 & 1 & 27 & 0 & 0 & 0 & 30 \\
\hline 3. Beliduwa Islands, Kalutara. & 18 & 2 & 0 & 16 & 0 & 0 & 0 & 18 \\
\hline 4. Cultural Center Muthurajawela & 518 & 8 & 2 & 478 & 26 & 1 & 3 & 518 \\
\hline 5. Industrial Estate, Kuruwita & 0 & 0 & 0 & 0 & 0 & 0 & 0 & 0 \\
\hline 6. Oil Storage Terminal, Sapugaskanda & 175 & 0 & 0 & 0 & 0 & 0 & 0 & 0 \\
\hline 7. Wax Match Industry, Matara & 0 & 0 & 0 & 0 & 0 & 0 & 0. & 0 \\
\hline 8. Town Development, Kalmunai & 0 & 0 & 0 & 0 & 0 & 0 & 0 & 0 \\
\hline 9. Industrial Estate, Mirigạma & 0 & 0 & 0 & 0 & 0 & 0 & 0 & 0 \\
\hline 10. Industrial Estate, Dankotuwa & 0 & 0 & 0 & 0 & 0 & 0 & 0 & 0 \\
\hline 11. Julia Lanka (Pvt) Ltd. & 0 & 0 & 0 & 0 & 0 & 0 & 0 & 0 \\
\hline 12. Randle's Hill Project, Hantana & 0 & 0 & 0 & 0 & 0 & 0 & 0 & 0 \\
\hline 13. Solid Waste Disposal, Koratota & 211 & 1 & 2 & 205 & 0 & 1 & 2 & 211 \\
\hline Total & 952 & 13 & 5 & 726 & 26 & 2 & 5 & 777 \\
\hline \multicolumn{9}{|l|}{ EIA } \\
\hline 1. Rajawella Golf \& Hotel Project & 176 & 2 & 3 & 6 & 0 & 0 & 0 & 11 \\
\hline 2. SamanalaWewa Wet Blanketing & 0 & 0. & 0 & 0 & 0 & 0 & 0 & 0 \\
\hline 3. Kerawalapitiya Reclamation Project & 365 & 5 & 1 & 237 & 0 & 2 & 0 & 245 \\
\hline 4. Colombo - Katunayake Expressway & 882 & 8 & 2 & 760 & 108 & 2 & 2 & 882 \\
\hline 5. LP Gas Terminal, Muthurajawela & 37 & 3 & 1 & 28 & 5 & 0 & 0 & 37 \\
\hline 6. Industrial Estate, Kalutara & 150 & 0 & 0 & 0 & 0 & 0 & 0 & 0 \\
\hline 7. Industrial Estate at Bata-atha & 529 & 5 & 1 & 462 & 0 & 0 & 1 & 469 \\
\hline 8. Upper Kotmale Hydro Power Project & 1610 & 10 & 5 & 1032 & 257 & 0 & 2 & 1306 \\
\hline 9. Sanitary Landfill, Alupothawatta & 1317 & 6 & 3 & 1122 & 86 & 0 & 0 & 1217 \\
\hline 10. Wirawila Walk Inn & 2 & 2 & 0 & 0 & 0 & 0 & 0 & 2 \\
\hline 11. SUVIC Hotel Project, & 0 & 0 & 0 & 0 & 0 & 0 & 0 & 0 \\
\hline 12. Aqua Pearl Villa, Bolgoda & 0 & 0 & 0 & 0 & 0 & 0 & 0 & \\
\hline 13. Southern Expressway & 2973 & 8 & 2 & 1965 & 420 & 2 & 1 & 2398 \\
\hline 14. Coal Power Plant, Kalpitiya & 2812 & 7 & 5 & 2280 & 508 & 3 & 9 & 2812 \\
\hline 15. Pelawatta Golf \& Hotel Project & 183 & 3 & 1 & 178 & 0 & 0 & 1 & 183 \\
\hline Total & 11036 & 59 & 24 & 8070 & 1384 & 9 & 16 & 9562 \\
\hline
\end{tabular}

NGO-Non Governmental Organisations, YO-Youth Organizations, RL-Residents of the Locality, NR-Non Residents, GM-Gramodaya Mandala and RO-Religious Organizations

the others. About four of the EIA category showed a very low level of participation quite similar to an average IEE. In both IEE \& EIA the largest number of responses had been from residents of the locality. For the 28 projects studied $30 \%$ of IEE \& $73 \%$ of EIA had attracted NGO responses. Out of 72 NGO responses, Upper Kotmale Hydropower project attracted the most (10). The Cultural Center Muthurajawela, ColomboKatunayaka and Southern Expressways (8 each), Coal Power Plant Kalpitiya (7) and Sanitary landfill Alupothawatta (6) are the other projects which had been responded to by NGO.
In the case of having public responses reaching nearly 200 or above religious organisations have been attracted to provide responses. In the case of EIA projects which had received large resident responses, there had also been significant non resident responses. If each project could be considered as having experienced public participation even if one person had participated, then $73 \%$ of EIA projects and $31 \%$ of IEE projects have had public comments.

This study did not attempt to assess the quality of EIA reports due to the lack of guidelines and 
also due to the differences in the contents. Therefore no assessment of the report quality in relation to the public comments/participation has been carried out.

\subsection{Achievement of Expected Participation}

An attempt was taken to look at participation in a quantitative manner. The issues that could be identified in an EIA could be categorized into six as 1) Socio-Economic Topics (SE), 2) Environment and Health Issues (E\&H), 3) Inadequacy in IEE/ EIA reports (IR), 4) Requests for Public Hearing $(\mathrm{PH}), 5)$ Cultural and Aesthetic (C\&A), and 6)
Other Issues (OI). When looking at the public responses with regard to these issues, it is fair to target a good response from each individual when atleast one comment has been sent in for each issue group. This means that if each response has at least six issues. EIA would then achieve the maximum participation expected by the project proponents and the approving authorities. Based on this assumption, the maximum number of responses that could be expected from participants were calculated and compared with the number of responses received. Achievement of Expected Participation (AEP) of each project was taken as the \% of responses in relation to the

Table 2: Achievement of Expected Participation (AEP) of the Studied IEE \& EIA Projects

\begin{tabular}{|c|c|c|c|c|c|c|}
\hline \multirow{2}{*}{$\begin{array}{c}\text { Name of the project } \\
\text { IEE }\end{array}$} & \multicolumn{6}{|c|}{ Maximum Expected Responses } \\
\hline & $\begin{array}{c}\text { Total } \\
\text { Respon- } \\
\text { ses }\end{array}$ & $\begin{array}{c}\text { Total } \\
\text { Respon- } \\
\text { dents }\end{array}$ & $\begin{array}{c}\text { AEP - One } \\
\text { Comment per } \\
\text { Issue Group }\end{array}$ & $\%$ & $\begin{array}{c}\text { If Commented } \\
\text { on } 50 \% \text { of } \\
\text { Issue Groups }\end{array}$ & $\%$ \\
\hline 1. Seethawaka Industrial Estate & 0 & 0 & 0 & 0 & 0 & 0 \\
\hline 2. Prawn Culture Project, Madilla & 34 & 30 & 180 & 19 & 90 & 38 \\
\hline 3. Beliduwa Islands, Kalutara & 31 & 18 & 108 & 29 & 54 & 57 \\
\hline 4. Cultural Center Muthurajawela & 613 & 518 & 3108 & 20 & 1554 & 39 \\
\hline 5. Industrial Estate, Kuruwita & 0 & 0 & 0 & 0 & 0 & 0 \\
\hline 6. Oil Storage Terminal, Sapugaskanda & 0 & 175 & 1050 & 0 & 525 & 0 \\
\hline 7. Wax Match Industry, Matara & 0 & 0 & 0 & 0 & 0 & 0 \\
\hline 8. Town Development, Kalmunai & 0 & 0 & 0 & 0 & 0 & 0 \\
\hline 9. Industrial Estate, Mirigama & 0 & 0 & 0 & 0 & 0 & 0 \\
\hline 10. Industrial Estate, Dankotuwa & 0 & 0 & 0 & 0 & 0 & 0 \\
\hline 11. Julia Lanka (Pvt) Ltd. & 0 & 0 & 0 & 0 & 0 & 0 \\
\hline 12. Randle's Hill Project, Hantana & 0 & 0 & 0 & 0 & 0 & 0 \\
\hline 13. Solid Waste Disposal, Koratota & 399 & 211 & 1266 & 32 & 633 & 63 \\
\hline Total & 1077 & 952 & 5712 & 19 & 2856 & 38 \\
\hline \multicolumn{7}{|l|}{ EIA } \\
\hline 1. Rajawella Golf \& Hotel Project & 18 & 176 & 1056 & 2 & 528 & 3 \\
\hline 2. SamanalaWewa Wet Blanketing & 0 & 0 & 0 & 0 & 0 & 0 \\
\hline 3. Kerawalapitiya Reclamation Project & 283 & 365 & 2190 & 13 & 1095 & 26 \\
\hline 4. Colombo - Katunayake Expressway & 1864 & 882 & 5292 & 35 & 2646 & 70 \\
\hline 5. LP Gas Terminal, Muthurajawela & 47 & 37 & 222 & 21 & 111 & 42 \\
\hline 6. Industrial Estate, Kalutara & 0 & 150 & 900 & 0 & 450 & 0 \\
\hline 7. Industrial Estate at Bata-atha & 574 & 529 & 3174 & 18 & 1587 & 36 \\
\hline 8. Upper Kotmale Hydro Power Project & 3093 & 1610 & 9660 & 32 & 4830 & 64 \\
\hline 9. Sanitary Landfill, Alupothawatta & 1790 & 1317 & 7902 & 23 & 3951 & 45 \\
\hline 10. Wirawila Walk Inn & 2 & 2 & 12 & 17 & 6 & 33 \\
\hline 11. SUVIC Hotel Project, Seeduwa & 0 & 0 & 0 & 0 & 0 & 0 \\
\hline 12. Aqua Pearl Villa, Bolgoda & 0 & 0 & 0 & 0 & 0 & 0 \\
\hline 13. Southern Expressway & 3750 & 2973 & 17838 & 21 & 8919 & 42 \\
\hline 14. Coal Power Plant, Kalpitiya & 7008 & 2812 & 16872 & 42 & 8436 & 83 \\
\hline 15. Pelawatta Golf \& Hotel Project & 306 & 183 & 1098 & 28 & 549 & 56 \\
\hline Total & 18735 & 11036 & 66216 & 28 & 33108 & 57 \\
\hline
\end{tabular}

( 
maximum expected responses. Computations for the selected environmental assessments revealed that the AEP was not very high. If the expectation of EIA promoters is for the public to comment on at least $50 \%$ of the issue groups then the present level of AEP would rise only to values as shown in the last column of Table 2. Since issues indicated in this Table have been grouped by looking at only a few degrees of freedom, it is felt that the AEP with $50 \%$ would be an exaggerated indicator for the achievement of expected participation. As such one needs to do a more detailed data analysis prior to arriving at an indicator for AEP.

It was found that the AEP in the case of IEE was having a maximum value of $32 \%$, whereas in the case of EIA the maximum was $42 \%$. In general for IEE projects that had public participation, the AEP was around $20 \%$ whereas for EIA it was around $28 \%$. In the entire data set taken for study, the low value of expected participation along with the identified characteristic that comments have been made only for negative aspects, reveals that their had been only a few matters of concern. The desire of the environmental administrators and project developers should be to encourage public responses for positive aspects of project as well and thereby increase the expected participation level of a project. At the same time project proponent could quantify the negative concerns and compare same with positive aspects for all considered alternatives to facilitate rational decision making for project implementation.

The analysis shows environment \& health, and cultural \& aesthetic issues are of significant interest in the case of both IEE \& EIA. The lesser significance given to IEE by environmental authorities is clearly visible with the low responses in the IR categories except for two projects which do not appear to fit in well with the rest of the IEE group projects.

With the increase of spatial extents covered by projects there appears a proportionate increase in the Socio Economic concerns. Comparison of public responses and the issues pertaining to report inadequacies, indicate that most concerns would probably have arisen due to inadequate details being provided in the environmental assessment reports.

\subsection{Issue Groups}

\subsubsection{Overall View}

Different issues raised by the public in their comments were summarized and it was found that the responses could be grouped into 6 categories (Section 3.2). The responses which did not raise any issue in a submission were not taken into consideration for grouping.

In the Socio-Economic issues, the loss of lands \& houses, the loss of jobs or income, and the loss of cultivation or cultivable land were concerns of the public. Air/Water/Noise pollution, the spreading of disease, and the impact of vulnerable groups were the issues grouped as environment and health issues. Inadequacy in alternative strategies, queries about the data used for the study, maintenance and operation and measures in mitigation, and difficulty in reading and understanding the technical jargon in EA reports were categorized as inadequacies in IEE/EIA reports. The other category consisted of legal issues, project financing concerns and the participant's indication of only a protest against the concerned development. Summary of findings is in Table 3. Responses for an issue group were compared with the total number of responses in the case of IEE \& EIA, respectively to take an overall view. In the IEEs, the C\&A category had most of the public comments (39\%) whereas comments on $\mathrm{E} \& \mathrm{H}$ and IR were around $20 \%$. Socio-Economic concerns had only $7 \%$. In the case of EIA, $32 \%$ of the comments were in the SE category whereas around $20 \%$ of the comments were under the $E \& H, I R$ and $C \& A$.

\subsubsection{Issue Emphasis by Respondents}

An assessment of participation in the case of each issue group can be looked at only by comparing the number of respondents for an issue group with the total number of respondents identified for that particular project (Table 2). However there is a lack of detail pertaining to the number of respondents for each group. Under the circumstances it was assumed that in each group each response belongs to a different respondent. Though there can be instances where a single respondent may send in more than one response for a particular group, by making computations assuming that the number of received responses per group (Table 3 ) is equal to the respondents per group, it is possible to arrive at an indicator 
Table 3: Public Responses for Different Issues in the Studied IEE \& EIA Projects

\begin{tabular}{|c|c|c|c|c|c|c|c|}
\hline Name of the project & \multicolumn{7}{|c|}{ Number of Public Responses under Each Issue Group } \\
\hline IEE & SE & $\mathrm{E} \& \mathrm{H}$ & IR & PH & C\&A & OI & Total \\
\hline 1. Seethawaka Industrial Estate & 0 & 0 & 0 & 0 & 0 & 0 & 0 \\
\hline 2. Prawn Culture Project, Madilla & 0 & 25 & 3 & 0 & 0 & 6 & 34 \\
\hline 3. Beliduwa Islands, Kalutara & 16 & 0 & 8 & 0 & 0 & 7 & 31 \\
\hline 4. Cultural Center Muthurajawela & 18 & 12 & 190 & 0 & 330 & 63 & 613 \\
\hline 5. Industrial Estate, Kuruwita & 0 & 0 & 0 & 0 & 0 & 0 & 0 \\
\hline 6. Oil Storage Terminal, Sapugaskanda & 0 & 0 & 0 & 0 & 0 & 0 & 0 \\
\hline 7. Wax Match Industry, Matara & 0 & 0 & 0 & 0 & 0 & 0 & 0 \\
\hline 8. Town Development, Kalmunai & 0 & 0 & 0 & 0 & 0 & 0 & 0 \\
\hline 9. Industrial Estate, Mirigama & 0 & 0 & 0 & 0 & 0 & 0 & 0 \\
\hline 10. Industrial Estate, Dankotuwa & 0 & 0 & 0 & 0 & 0 & 0 & 0 \\
\hline 11. Julia Lanka (Pvt) Ltd. & 0 & 0 & 0 & 0 & 0 & 0 & 0 \\
\hline 12. Randle's Hill Project, Hantana & 0 & 0 & 0 & 0 & 0 & 0 & 0 \\
\hline 13. Solid Waste Disposal, Koratota & 37 & 177 & 44 & 0 & 95 & 46 & 399 \\
\hline Total & $\begin{array}{c}71 \\
(7 \%)\end{array}$ & $\begin{array}{c}214 \\
(20 \%)\end{array}$ & $\begin{array}{c}245 \\
(23 \%)\end{array}$ & 0 & $\begin{array}{c}425 \\
(39 \%)\end{array}$ & $\begin{array}{c}122 \\
(11 \%)\end{array}$ & 1077 \\
\hline \multicolumn{8}{|l|}{ EIA } \\
\hline 1. Rajawella Golf \& Hotel Project & 10 & 3 & 3 & 2 & 0 & 0 & 18 \\
\hline 2. SamanalaWewa Wet Blanketing & 0 & 0 & 0 & 0 & 0 & 0 & 0 \\
\hline 3. Kerawalapitiya Reclamation Project & 239 & 21 & 5 & 0 & 0 & 18 & 283 \\
\hline 4. Colombo - Katunayake Expressway & 860 & 134 & $665^{\circ}$ & 16 & 84 & 105 & 1864 \\
\hline 5. LP Gas Terminal, Muthurajawela & 20 & 25 & 2 & 0 & 0 & 0 & 47 \\
\hline 6. Industrial Estate, Kalutara & 0 & 0 & 0 & 0 & 0 & 0 & $0^{\circ}$ \\
\hline 7. Industrial Estate at Bata-atha & 10 & 190 & 328 & 12 & $\dot{0}$ & 34 & 574 \\
\hline 8. Upper Kotmale Hydro Power Project & 1005 & 365 & 291 & 176 & 936 & 320 & 3093 \\
\hline 9. Sanitary Landfill, Alupothawatta & 2 & 970 & 274 & 0 & 366 & 178 & 1790 \\
\hline 10. Wirawila Walk Inn & 2 & 0 & 0 & 0 & 0 & 0 & 2 \\
\hline 11. SUVIC Hotel Project, Seeduwa & 0 & 0 & 0 & 0 & 0 & 0 & 0 \\
\hline 12. Aqua Pearl Villa, Bolgoda & 0 & 0 & 0 & 0 & 0 & 0 & 0 \\
\hline 13. Southern Expressway & 1805 & 402 & 790 & 179 & 295 & 279 & 3750 \\
\hline 14. Coal Power Plant, Kalpitiya & 1978 & 1465 & 760 & 306 & 2010 & 489 & 7008 \\
\hline 15. Pelawatta Golf \& Hotel Project & 12 & 159 & 22 & 0 & 78 & 35 & 306 \\
\hline Total & $\begin{array}{c}5943 \\
(32 \%)\end{array}$ & $\begin{array}{c}3734 \\
(20 \%)\end{array}$ & $\begin{array}{c}3140 \\
(17 \%)\end{array}$ & $\begin{array}{c}691 \\
(4 \%)\end{array}$ & $\begin{array}{c}3769 \\
(20 \%)\end{array}$ & $\begin{array}{l}1458 \\
(8 \%)\end{array}$ & 18735 \\
\hline
\end{tabular}

1) Socio-Economic Topics (SE), Environment and Health Issues (ESH), Inadequacy in Reports (IR), Requests for Public Hearing (PH), Cultural and Acsthetic (CEA), Other Issues (OI).

which is closer to the upper bound indicator of "Issue emphasis by Respondents (IER)". Once these values are estimated, it is easier to assess the present levels of participation. This indicator IER was computed and the results are presented in Table 4.

The IER percentage values obtained for each group or issues were averaged to calculate the degree of participation in the project where the number of persons who participated was greater than zero. In the case of IEE, the average degree of participation was highest in the E\&H group with $42 \%$ while all other groups except public hearing had an average level of participation of around $25 \%$. Public hearing is not much of a relevance to IEE projects and hence the zero is justifiable. In the case of EIA, the SE issues were prominent with an average degree of participation of $61 \%$. With a value of $38 \%$ the E\&H issues in the case of EIA showed a similar average level of participation. In EIA, comments were focused within the 5 key issue groups to IEE and this was evident by the $10 \%$ level of 
Table 4: Issue Emphasis by Respondents (IER) for the Studied IEE \& EIA Projects

\begin{tabular}{|c|c|c|c|c|c|c|}
\hline Name of the project & \multicolumn{6}{|c|}{ IER under Each Issue Group ( $\%)$} \\
\hline IEE & $\mathrm{SE}$ & $\mathrm{E \& H}$ & IR & PH & C\&A & $\mathrm{OI}$ \\
\hline 1. Seethawaka Industrial Estate & 0 & 0 & 0 & 0 & 0 & 0 \\
\hline 2. Prawn Culture Project, Madilla & 0 & 83 & 10 & 0 & 0 & 20 \\
\hline 3. Beliduwa Islands, Kalutara & 89 & 0 & 44 & 0 & 0 & 39 \\
\hline 4. Cultural Center Muthurajawela & 3 & 2 & 37 & 0 & 64 & 12 \\
\hline 5. Industrial Estate, Kuruwita & 0 & 0 & 0 & 0 & 0 & 0 \\
\hline 6. Oil Storage Terminal, Sapugaskanda & 0 & 0 & 0 & 0 & 0 & 0 \\
\hline 7. Wax Match Industry, Matara & 0 & 0 & $0^{\circ}$ & 0 & 0 & 0 \\
\hline 8. Town Development, Kalmunai & 0 & 0 & 0 & 0 & 0 & 0 \\
\hline 9. Industrial Estate, Mirigama & 0 & 0 & 0 & 0 & 0 & 0 \\
\hline 10. Industrial Estate, Dankotuwa & 0 & 0 & 0 & 0 & 0 & 0 \\
\hline 11. Julia Lanka (Pvt) Ltd. & 0 & 0 & 0 & 0 & 0 & 0 \\
\hline 12. Randle's Hill Project, Hantana & 0 & 0 & 0 & 0 & 0 & 0 \\
\hline 13. Solid Waste Disposal, Koratota & 18 & 84 & 21 & 0 & 45 & 22 \\
\hline Average from Participated Projects & 27 & 42 & 28 & 0 & 27 & 23 \\
\hline \multicolumn{7}{|l|}{ EIA } \\
\hline 1. Rajawella Golf \& Hotel Project & 91 & 27 & 27 & 18 & 0 & 0 \\
\hline 2. SamanalaWewa Wet Blanketing & 0 & 0 & 0 & 0 & 0 & 0 \\
\hline 3. Kerawalapitiya Reclamation Project & 98 & 9 & 2 & 0 & 0 & 7 \\
\hline 4. Colombo-Katunayake Expressway & 98 & 15 & 75 & 2 & 10 & 12 \\
\hline 5. LP Gas Terminal, Muthurajawela & 54 & 68 & 5 & 0 & 0 & 0 \\
\hline 6. Industrial Estate, Kalutara & 0 & 0 & 0 & 0 & 0 & 0 \\
\hline 7. Industrial Estate at Bata-atha & 2 & 41 & 70 & 3 & 0 & 7 \\
\hline 8. Upper Kotmale Hydro Power Project & 77 & 28 & 22 & 13 & 72 & 25 \\
\hline 9. Sanitary Landfill, Alupothawatta & 0 & 80 & 23 & 0 & 30 & 15 \\
\hline 10. Wirawila Walk Inn100 & 0 & 0 & 0 & 0 & 0 & \\
\hline 11. SUVIC Hotel Project, Seeduwa & 0 & 0 & 0 & 0 & 0 & 0 \\
\hline 12. Aqua Pearl Villa, Bolgoda & 0 & 0 & 0 & 0 & 0 & 0 \\
\hline 13. Southern Expressway & 75 & 17 & 33 & 7 & 12 & 12 \\
\hline 14. Coal Power Plant, Kalpitiya & 70 & 52 & 27 & 11 & 71 & 17 \\
\hline 15. Pelawatta Golf \& Hotel Project & 7 & 87 & 12 & 0 & 43 & 19 \\
\hline Average from Participated Projects & 61 & 38 & 27 & 5 & 22 & 10 \\
\hline
\end{tabular}

1) Socio-Economic Topics (SE), Environment and Health Issues (E\&H), Inadequacy in Reports (IR), Requests for Public Hearing (PH), Cultural and Aesthetic (CEA), Other Issues (OI).

participation when compared with the $23 \%$ of IEEs in the case of other issues (Table 4). The C\&A group in EIA showed a lower response from the public at $22 \%$ whereas report inadequacies were equally highlighted at a public participation level of $27 \%$ in the case of EIAs too.

\subsection{EIA Stages}

According to the NEA the public can participate in five stages of the EA process i.e. 1) Scoping, 2) Meeting with the Public 3) Public Comment Period 4) Public Hearing 5) Appeals. The number of persons who participated was listed at each stage for each project (Table 5).
The records indicated that no person had participated in Scoping for both IEE and EIA. Only those who were involved in the preparation of EIA and the government servants had participated in this activity. Records also did not indicate the participation of NGO in Scoping.

A comparison of the two types of EA on projects showed that in the case- $\theta$ f-projects identified as having fewer impacts on the environment, the public participation was very low. Of the total number of nearly 12,000 persons who participated in an almost equal number of projects from each group indicated that $92 \%$ of the public participation was attracted by the EIA projects. 
Table 5: Public Responses at Different Stages in the Studied IEE \& EIA Projects

\begin{tabular}{|c|c|c|c|c|c|c|}
\hline Name of the project & \multicolumn{6}{|c|}{ Stagewise Involvement (persons) } \\
\hline IEE & Scoping & $\begin{array}{c}\text { Meetings } \\
\text { with } \\
\text { Public }\end{array}$ & $\begin{array}{c}\text { Public } \\
\text { Comments }\end{array}$ & \begin{tabular}{|c|} 
Public \\
Hearing
\end{tabular} & Appeals & Total \\
\hline 1. Seethawaka Industrial Estate & 0 & 0 & 0 & 0 & 0 . & 0 \\
\hline 2. Prawn Culture Project, Madilla & 0 & 0 & 30 & 0 & 0 & 30 \\
\hline 3. Beliduwa Islands, Kalutara & 0 & 0 & 18 & 0 & 0 & 18 \\
\hline 4. Cultural Center Muthurajawela & 0 & 0 & 518 & 0 & 0 & 518 \\
\hline 5. Industrial Estate, Kuruwita & 0 & 0 & 0 & 0 & 0 & 0 \\
\hline 6. Oil Storage Terminal, Sapugaskanda & 0 & 175 & 0 & 0 & 0 & 175 \\
\hline 7. Wax Match Industry, Matara & 0 & 0 & 0 & 0 & 0 & 0 \\
\hline 8. Town Development, Kalmunai & 0 & 0 & 0 & 0 & 0 & 0 \\
\hline 9. Industrial Estate, Mirigama & 0 & 0 & 0 & 0 & 0 & 0 \\
\hline 10. Industrial Estate, Dankotuwa & 0 & 0 & 0 & 0 & 0 & 0 \\
\hline 11. Julia Lanka (Pvt) Ltd. & 0 & 0 & 0 & 0 & 0 & 0 \\
\hline 12. Randle's Hill Project, Hantana & 0 & 0 & 0 & 0 & 0 & 0 \\
\hline 13. Solid Waste Disposal, Koratota & 0 & 0 & 211 & 0 & 0 & 211 \\
\hline Total & 0 & 175 & 777 & 0 & 0 & 952 \\
\hline \multicolumn{7}{|l|}{ EIA } \\
\hline 1. Rajawella Golf \& Hotel Project & 0 & 160 & 11 & 0 & 5 & 176 \\
\hline 2. SamanalaWewa Wet Blanketing & 0 & 0 & 0 & 0 & 0 & 0 \\
\hline 3. Kerawalapitiya Reclamation Project & 0 & 120 & 245 & 0 & 0 & 365 \\
\hline 4. Colombo - Katunayake Expressway & 0 & 0 & 882 & 0 & 0 & 882 \\
\hline 5. LP Gas Terminal, Muthurajawela & 0 & 0 & 37 & 0 & 0 & 37 \\
\hline 6. Industrial Estate, Kalutara & 0 & 150 & 0 & 0 & 0 & 150 \\
\hline 7. Industrial Estate at Bata-atha & 0 & 60 & 469 & 0 & 0 & 529 \\
\hline 8. Upper Kotmale Hydro Power Project & 0 & 0 & 1306 & 300 & 4 & 1610 \\
\hline 9. Sanitary Landfill, Alupothawatta & 0 & 100 & 1217 & 0 & 0 & 1317 \\
\hline 10. Wirawila Walk Inn & 0 & 0 & 2 & 0 & 0 & 2 \\
\hline 11. SUVIC Hotel Project, Seeduwa & 0 & 0 & 0 & 0 & 0 & 0 \\
\hline 12. Aqua Pearl Villa, Bolgoda & 0 & 0 & 0 & 0 & 0 & 0 \\
\hline 13. Southern Expressway & 0 & 400 & 2398 & 175 & 0 & 2973 \\
\hline 14. Coal Power Plant, Kalpitiya & 0 & 0 & 2812 & 0 & 0 & 2812 \\
\hline 15. Pelawatta Golf \& Hotel Project & 0 & 0 & 183 & 0 & 0 & 183 \\
\hline Total & 0 & 990 & 9562 & 475 & 9 & 11036 \\
\hline
\end{tabular}

The conduct of meetings with public has not been carried out in many projects. In the records, not much importance was given to such meetings or awareness programs. It was noted that in the projects which received high media attention such as the Katunayaka Expressway and the Upper Kotmale Hydropower Project, the interest to conduct such meetings or awareness programs had arisen when the project had become controversial and was criticized. The majority of public participation was during the public commenting period and during data collection. It was noted that NGO were playing a prominent role in this activity in educating the public on their rights as indicated in the NEA. It was also noted that in some projects though there had been participation during meetings, no comments from such personnel were in the records.

Public participation is highest in the public commenting period. In general for IEE projects the participation during public comment period is about $82 \%$ of the contribution at all stages. For EIA projects this is approximately $87 \%$. It was interesting to note that in this period, out of more than 10,000 comments $58 \%$ were received for projects which had not held public meetings. 
Public hearings are held at the discretion of the Project Approving Agency (PAA) when there is a public interest. By definition, for IEE public hearing is not much applicable and this is also visible from the collected data. In the case of some EIAs also no public hearing has taken place. In general approximately $4 \%$ of participation could be observed for EIA projects.

EIA appeals are not common to all the selected projects. Appeals against a decision on a project can be made only by the developer and not by the public. Therefore it is noted that public participation during appeals is poor for the majority of projects.

\section{Conclusions and Recommendations}

1) Comparing the numbers and percentages of participation in general for IEE projects and EIA projects the public participation is minimal in IEE. One reason is the IEE and EIA classification. In the present method of classification there are a few IEE projects that attracted public comments similar to an EIA and vice versa. By improving the methodology to clearly identify the IEE and EIA projects, it is possible to reduce the public participation period of lower impact projects thereby facilitating an early project commencement and thus contributing to the national economy. This irregularity in importance shown by the public gives rise to the need to review the current division of the environmental review process with a view to have an improved classification of IEE and EIA.

2) During the data collection process, it was identified that, as at present, the data in reports and files do not provide any straightforward presentation of the details of public participation and this creates difficulty in assessments. Since public participation in EA is vital, action needs to be effected to provide guidelines for proper documentation of such details.

3) On average, the overall expected participation in IEE and EIA were in the range of $20-30 \%$ and this reflects a low level because the overall participation is computed having regard to the public responses received for both positive and negative aspects. However since the tendency of the public is to comment basically on the negative impacts, the low level of Degree of Participation indicates that the projects have not had much significant negative environmental concerns. The indicator "Achievement of Expected Participation (AEP)" could be effectively used to identify the balance of participation for positive and negative issues.

4) The "Issue Emphasis by Respondents (IER)" indicates the public concerns for different types of issues. It was identified that in EIA most of the concerns were in the SocioEconomic category $(61 \%)$ indicating that it may be necessary to either strengthen the EIAs in this aspect or a decision made whether a separate Social Impact Assessment needs to be carried out to supplement the EA reports. However the environmental concerns were the next in EIAs with approximately $40 \%$ of participation. In the case of IEE, Environmental and Health concerns were prominent with $42 \%$ of participation while the other issues were of lesser importance.

5) Public involvement during Scoping is alarming with a participation value of zero. Therefore it may be prudent to carry out a detailed study whether it is necessary to encourage the public to participate from the beginning so that development projects be started early without much public protest and associated delays. It is strongly felt that initial identification of the public concerns would facilitate the tasks of EIA preparers and also rectify concerns with respect to the report inadequacies. This would ensure early clearance for development activities.

6) Public participation during meetings or the meetings with public was a rarity. The low number of comments during the public comment period for the projects that had held meetings suggests the possibility that it may be advantageous in the long run to hold meetings at the beginning to ensure public acceptance which would lead to early implementation of projects.

7) The results of this work could identify the importance of a quantitative analysis in establishing the status of public participation with respect to EA. As such the present study indicated that a quantitative approach could be effected without great difficulty. 
8) The total number of respondents for EIA projects which are mostly national projects covering large spatial extents had been 11036 . With a maximum number for a single project being 2973. It is well known that on many occasions, as it has been reported in the media, that the public responses do create significant delays in the case of national projects. Several such project proposals are the Upper Kotmale Hydropower Project, the Coal Power Projects, the Colombo Solid Waste Development Projects, the Southern Highway Project etc This study brings to light the need for the identification of a threshold "Public Response" for implementation by considering the percentage of the nation served by the project in relation to the issues and number of responses raised by the affected. A further study may need to look at the relationship to the delay of a project implementation in the light of public participation, improper planning, insufficient public notice etc.

\section{Acknowledgements}

Most of the results presented in this work were executed as part of the Masters of Engineering Thesis of the second author which was submitted to the University of Moratuwa. The support given by the Central Environmental Authority, the International Union for Conservation of Nature, Sri Lanka Environmental Assessment Association of Sri Lanka is gratefully acknowledged.

\section{References}

1. CEA 1993 Guidelines for implementing the EIA Process - No. 1, A General Guide for Project Approving Agencies, Central Environmental Authority, Sri Lanka

2. CEA 1988 Guidelines for implementing the EIA Process - No. 3, Public Participation Handbook, Central Environmental Authority, Sri Lanka

3. Jayawickrama 1997 Jayawickrama S.S., Developers' View of EIA, Environmental Impact Assessment - The Sri Lankan Experience, Center for Environmental Studies, University of Peradeniya, Sri Lanka

4. NEA 1988 National Environmental Act No. 47 of 1980 and Amendment Act No 56 of 1988, Part IV C, Approval of Projects, Government of Sri Lanka

5. Weerakkody 2000 Weerakkody N.C., Evaluation of Public Participation and Methodologies Adopted in Environmental Impact Assessment Process in Sri Lanka, M.Eng Thesis submitted to University of Moratuwa Sri Lanka, November (Unpublished)

6. Wijesekera 1999 Wijesekera N.T.S., EIA System in Sri Lanka, Country Report, First Annual South Asian Environment Assessment Conference, IUCN, Katmandu, Nepal, December

7. Withanage 1997 Withanage. H., Public Participation in Environmental Impact Assessment, Environmental Impact Assessment - The Sri Lankan Experience, Center for Environmental Studies, University of Peradeniya, Sri Lanka 